\title{
IMPLANTAÇÃO DO PROGRAMA CASA DE PARTO DO ESTADO DA BAHIA
}

\author{
Maria Nydia Tavares Bittencourt ${ }^{1}$
}

\begin{abstract}
RESUMO. O Projeto Casa de Parto tem como objetivo geral ampliar e melhorar a assis. tência ao grupo Materno-Infantil, sendo usados como plano piloto 44 municípios do Estado da Bahia. Consiste basicamente na introdução de Unidades de Saúde, constituídas de nove leitos, centro obstétrico, isolamento e consultório para atendimento externo na rede tradicional de atenção primária. Na Unidade será prestada assistência pré-natal, ao parto natural, visita domiciliar à puérpera-criança, trabalho com curiosa, puericultura, educação em saúde, formação de creche e horta comunitária. A equipe é constituída de uma enfermeira obstetra, quatro atendentes de enfermagem, sendo todos os elementos submetidos a treinamento de noventa dias, sobre a metodologia e filosofia do trabalho desenvolvido na Unidade. Todos os profissionais atuam em regime de dedicação exclusiva, sendo coordenados pela enfermeira.
\end{abstract}

\begin{abstract}
A pilot plan of a Birth Houses Project is being developed In 44 localities in the state of Bahia. The main objective of this project is to improve health care to mothers and children by the introduction of health units with an obstetric center. a nine beds ward, an isolation area and ambulatory offices. These units are planned to give pre and post-natal assistance, natural birth, domiciliary visits, day nursery, health education and vegetable-garden. Its staff consists of an obstetric nurse and four health auxiliaries with special training period of ninety days.
\end{abstract}

\section{INTRODUÇÃO}

Após uma avaliação do serviço prestado ao grupo materno-infantil pelo Instituto de Saúde do Estado da Bahia, foi observado que essa assistência se limitava à atenção ao parto em unidade hospitalar e aos cuidados com a gestante e criança a nível de centros e postos de saúde. Considerando que a atenção primária de saúde no Brasil não pode ser concebida apenas como mais um elemento dos discursos oficiais, surgiu a idéia de se adicionar Unidade de Saúde, com a denominação de "Casa de Parto" à rede tradicional de atenção primária.
Essa proposta coerente com o objetivo da Política Nacional de Saúde para com a população materno-infantil teria como objetivo geral reduzir a mortalidade e a morbidade materno-infantil, através a implantação de uma Unidade simplificada de atenção à mulher na idade fértil e à criança de zero a catorze anos.

\section{CARACTERISTICA BASICA DO PROGRAMA}

A "Casa de Parto" é constituída de duas enfermarias com um total de seis leitos, um

1. Enfermeira sanitarista coordenadora do Programa Materno-Infantil da Secretaria da Saúde do Estado da Bahia. COREN-BA 592. 
isolamento com um leito, um pré-parto com dois leitos, um centro obstétrico e um consultório para atendimento externo.

O projeto foi implantado em 45 municípios, distribuídos em doze diretorias regionais, propondo-se a cobrir uma população constituída por 33.241 gestantes e de crianças de zero a quinze anos, num total de 271.037.

O programa inclui basicamente os seguintes objetivos:

- Propiciar assistência precocemente à mulher de forma contínua e periódica durante a gestação, o parto e puerpério iniciado por um pré-natal eficiente.

- Propiciar assistência à criança de zero a catorze anos.

- Participar do programa de diarréia através da orientação e administração da hidratação oral e o incentivo ao aleitamento materno.

- Desenvolver o trabalho com as parteiras, capacitando-as e supervisionando-as, criando com isso um elo de ligação e obtendo participação das mesmas com a Unidade.

- Desenvolver um trabalho comunitário com a criação de creches e hortas.

- Orientar toda a população em noções de saneamento básico,

- Desenvolver através de discussões de grupo, a importância da participação da mulher no desenvolvimento econômico e social da comunidade.

A equipe que compõe a "Casa de Parto" é constituída de uma enfermeira obstetra, quatro agentes de saúde e dois agentes de portaria, sendo todos os elementos submetidos a treinamento de noventa dias, sobre a metodologia e filosofia do trabalho desenvolvido na Unidade.

Todo o pessoal atua em regime de dedicação exclusiva, sendo coordenado pela enfermeira.

\section{ALGUNS ASPECTOS DA IMPLANTAÇÃO DO PROGRAMA}

Para a coordenação do programa, foi designada uma enfermeira, com a responsabilidade de agilizar as providências necessárias à sua implantação.

Foi em seguida elaborada a planta física e um cálculo de custos de implantação relativos a cada unidade. A partir daí, foram selecionados os municípios que iriam compor o programa, levando-se em conta critérios como população média de 15.000 habitantes e ausência de unidades de saúde com leitos para in- ternação. Após a escolha dos 45 municípios, procedeu-se a um estudo para determinar os hospitais de referência para aqueles casos cuja complexidade não permitisse a solıção a nível das "Casas de Parto".

Tendo sido estabelecido o quadro de pes soal para cada Unidade, conforme referido anteriormente, iniciou-se o processo de treinamento do pessoal, que obedeceu à seguinte metodologia. As enfermeiras cumpriram um período de noventa dias de treinamento prático em maternidade, onde reciclaram os seus conhecimentos obstétricos, além de receberem orientação em trabalho comunitário, onde foram enfatizadas técnicas de abordagem de comunidade. Chegando ao seu local de trabalho, as enfermeiras eram responsáveis pelo treinamento do pessoal auxiliar, que constou de sessenta dias de preparação em técnicas de enfermagem em geral, e mais trinta dias de treinamento específico em obstetrícia e trabalho comunitário. Esse treinamento foi orientado por manuais elaborados pelo Centro de Recursos Humanos da Instituição. Além da preparação do pessoal através dos cursos já referidos, foi elaborado um "Manual de Atividades para Casa de Parto", onde estão descritas todas as atribuições do pessoal de enfermagem referentes ao desenvolvimento do programa. O Manual foi, então, implantado pela coordenação do programa nas unidades em funcionamento, com a orientação de que o mesmo seja utilizado durante um ano, em fase experimental. Após esse período, deverá ser realizado um Seminário para reavaliação do Manual onde serão discutidas as sugestões dos profissionais que o utilizaram, visando a elaboração de um documento mais aproximado à prática local.

Entre as providências necessárias à implantação do Programa, foi ainda estabelecida uma verba para manutenção de cada unidade durante trinta dias, recurso este a ser administrado pela enfermeira coordenadora da "Casa de Parto".

A não previsão de espaço físico na planta da Unidade para funcionamento de serviços de lavanderia e nutrição, deve-se à determinação de que esses serviços sejam realizados por pessoas da comunidade, sob supervisão e orientação do pessoal da unidade.

Um outro aspecto importante a ser destacado no Programa é a incorporação das "parteiras curiosas". Para isso, as enfermeiras realizam um levantamento dessas parteiras em cada região, pois, em seguida, devem ser treinadas pela própria enfermeira. A partir daí, 
seus partos passam a ser supervisionados e até realizados na própria "Casa de Parto", criando-se assim uma oportunidade de maior interação e confiança entre os dois agentes (enfermeira e "curiosa") e a população de gestantes atendida.

\section{DESENVOLVIMENTO DAS ATIVIDADES}

Após a preparação da equipe que compõe o quadro de pessoal da Casa de Parto, a proposta é que o trabalho se desenvolva conjuntamente, englobando a realização de exames, avaliação periódica da gestação, trabalhos comunitários de educação para a saúde. Com isso objetiva-se que as ações integradas preventivas e de atenção ao momento do nascimento, transformem a gestação e o parto em um processo normal, que traga um mínimo de riscos para a mãe e para a criança. Constituemse elementos importantes nesse processo 0 conhecimento individualizado de cada paciente, bem como da cultura de cada comunidade, que devem ser a base para a implementação de medidas educativas, a fim de que essas possam obter algum nível de efetividade.

Nesse contexto, as ações de enfermagem que estão sendo privilegiadas no momento para serem desenvolvidas pela equipe da Casa de Parto constituem-se nas seguintes:

Consulta de enfermagem à gestante. Realiza-se uma anamnese que contempla aspectos não apenas biológicos, mas também os sociais e econômicos. Em seguida, procede-se ao exame obstétrico, com os procedimentos específicos que compõem o mesmo. Quando detectada uma gravidez de alto risco, a gestante é encaminhada ao Serviço Médico mais próximo. Ao mesmo tempo é fornecida orientação em relação aos problemas identificados, destacando-se informações sobre puerpério, cuidados com a criança e com a mama, além de orientar sobre medidas gerais de proteção à saúde.

Consulta de enfermagem à criança de zero a catorze anos. Realiza-se uma anamnese que contempla aspectos não apenas biológicos, mas também sociais e econômicos. Em seguida procede-se ao exame físico com os procedimentos específicos que compõem o mesmo. Quando detectada uma patologia, a criança é encaminhada ao serviço médico mais próximu. Além disso, administra-se o esquema de imunização adequado para cada grupo etário, faz-se a orientação quanto à higiene corporal e alimentar.
Formaçāo de grupos de gestantes, nutrizes, mães a adolescentes. Através de palestras, demonstrações e dramatizações ou discussões em grupo, são abordados temas, como por exemplo: evolução da gestação, parto, puerpério, desenvolvimento da criança, orientação para uma amamentação correta, higiene alimentar do adultc e criança, imunização do bebê, reprodução e planejamento familiar, economia do lar e higiene individual, entre outros. Aproveita-se ainda essa oportunidade para discutir com a mulher a importância da sua participação no desenvolvimento social e econômico, bem como na estruturação da sua comunidade. Com esses grupos formados, constituem-se ainda núcleos de planejamento e organização de hortas e creches comunitárias.

Organização de trabalhos com elementos leigos da comunidade. O exemplo de maior importância na área materno-infantil é a "Curiosa". Em localidades da área rural, a curiosa, através de sua liderança, constitui um elemento importantíssimo no desenvolvimento e sucesso das ações de saúde, por essa razão ela é incorporada pela equipe da "Casa de Parto", conforme já foi referido anteriormente, tornando-se indispensável no alcance das metas do programa. O trabalho da curiosa não é restrito somente às gestantes, mas são incorporadas às suas atividades, a notificação de doenças transmissíveis e encaminhamento de crianças para imunização. No trabalho dos leigos da comunidade também participam grupos de jovens, fornecendo-se a eles orientações sobre ações em saúde e transformando-os em pelotões de saúde, com a responsabilidade de fazer notificações de doenças transmissíveis, encaminhamento de gestantes e crianças sadias aos serviços de saúde, orientação de saneamento básico e higiere alimentar.

Visita domiciliar à puérpera e à criança. A visita é realizada por um elemento da equipe. Nessa oportunidade é feita a supervisão do curativo umbilical e perineal, do banho do bebê, retirando dúvidas, lembrando a importância de freqüentar a Unidade para revisão e início do esquema vacinal da criança. $\mathrm{Na}$ ocasião da visita é realizado um levantamento das condições de saneamento básico da habitação e estado vacinal das crianças. Aproveita-se ainda para repassar a orientação sobre condições básicas de higiene alimentar, saneamento básico e a importância de realizar todo o esquema de vacinação das crianças.

Atenção ao parto natural. Os partos são 
realizados pela enfermeira na unidade, encaminhando-se para os hospitais de referência apenas as distócias obstétricas e gestantes de alto risco.

Prevenção do câncer ginecológico. Durante a consulta de enfermagem realiza-se a colheita de material do colo uterino, que é fixado na lâmina, e enviado para o laboratório central em Salvador pelo correio, onde vai ser examinado. Em caso de laudo positivo o resultado é enviado através do serviço social, tomando-se em seguida, as providências necessárias a cada caso.

\section{CONCLUSÃO}

Após a colocação da atuação da enfermagem no desenvolvimento das atividades da "Casa de Parto" fica clara a responsabilidade que a mesma tem perante a comunidade.

E entretanto provável que, em muitos momentos, o acúmulo de tarefas vá impedir

\section{BIBLIOGRAFIA}

1. BRASIL. Ministério da Saúde. Padrões mínimos de assistência de enfermagem à comunidade: informe final. Brasília, 1977. $71 \mathrm{p}$.

2. BRASIL. Ministério da Saúde. Secretaria Nacional de Programas Especiais de Saúde. Divisão Nacional de Saúde Materno-Infantil. Normas narn a identificacão e controle dos riscos reprodutivo, obstétrico e da infertilidade no programa de saude materno-infantil. Brasilia, 1978. $32 \mathrm{p}$.

3. CONFERENCIA NACIONAL DE SAƯDE, 5., Brasília, 5 a 8 de agosto de 1975. Anais. Brasília, Ministério da Saúde, 1975. 399 p.

4. CURSO SOBRE ATENCION DE ENFERMERIA que a enfermeira cumpra na íntegra todo o programa previsto. Procurou-se, pois, durante todo o tempo de preparo do grupo, transmitir a importância do trabalho em equipe, para que todos possam assumir em conjunto as atividades de atenção à gestante, à puérpera, à nutriz, à mãe e à criança.

Realizou-se uma avaliação preliminar do Programa a partir dos dados coletados do relatório trimestral, mapa de produção e nas viagens de supervisão.

Estes dados parecem indicar que o Programa tem tido boa receptividade por parte da população, embora ainda não sejam suficientes para avaliar seu impacto na assistência materno-infantil.

BITTENCOURT, M. N. T. Birth houses in Bahia. Rev. Bras. Enf., Brasília, 37(2): 135-138, 1984.

\section{CONSULTADA}

OBSTETRICA EN PROGRAMAS DE SALUD MATERNO-INFANTIL, 2., Montevideo, 8-24 de septiembre de 1975. Normas de atencion de enfermeria obstétrica en el parto prematuro. Washington, Organizacion Panamericana de la Salud, 1978. $37 \mathrm{p}$.

5. MAMEDE, M. V. et alii. Importância da amamentação no relacionamento saúdável mãe e filho. Rev. Bras. Enf., Brasília, 32(3): 299-302, jul./set. 1979.

6. POLfTICA de saúde materno-infantil. s.n.t 23 p.

7. TROGER, A. L. M. A saúde da gestante. Rev. Bras. Enf., Brasília, 32(3): 255-8, jul./set. 1979. 